\title{
New developments in the asymmetric synthesis of heterocyclic natural products
}

\author{
Isabelle Baussanne, Bruno Dudot, Joëlle Pérard-Viret, Loïc Planas, and Jacques Royer* \\ Synthèse et structure de molécules d'intérêt pharmacologique (UMR 8638 CNRS-Université \\ Paris 5), Faculté de Pharmacie, 4 avenue de l'Observatoire, 75006 Paris cedex, France \\ E-mail : jacques.royer@univ-paris5.fr
}

\begin{abstract}
Various chiral $\alpha, \beta$-unsaturated $\gamma$-lactams 1 were prepared in high yield and in a single step from corresponding primary amines. The different reactivities of lactams $\mathbf{1}$ could be exploited to prepare diversely substituted pyrrolidones, pyrrolidines, $\gamma$-aminoacids and alkaloids. Their application to the synthesis of enantiomerically pure (-)-cephalotaxine are described.
\end{abstract}

Keywords: Asymmetric synthesis, alkaloid, lactam, pyrrolidine, cephalotaxine

\section{Contents}

1. Chiral $\alpha, \beta$-unsaturated $\gamma$-lactam

1.1 Preparation

1.2. Reactivity

2. Application to the synthesis of alkaloids

2.1 Asymmetric synthesis of polyhydroxylated pyrrolidines and indolizidines

2.2 Asymmetric synthesis of (-)-cephalotaxine

2.2.1 Cephalotaxine and homoharringtonine

2.2.2 Previous total syntheses and enantiomeric purity

2.2.3 Retrosynthesis

2.2.4 Synthesis of enantiomerically pure spiro compound

2.2.5 Completion of the synthesis of (-)-cephalotaxine 


\section{Introduction}

The synthesis of natural products and the total synthesis in general, requires the use of known reactions and methods to attain the construction of rings, chains, functionalities and their linkage in a specific manner in the respect of the stereochemistry of the target molecule. In this context, new methods are still needed to allow the synthesis of complex structures. The design, the preparation and the use of compounds containing several functionalities which can be specifically disclosed has been studied in our laboratory and found to be a very successful method for the synthesis of nitrogen heterocyclic structures. To be efficient, these substructures should be very easily accessible in high yield from cheap starting material.

We will first describe the preparation of a chiral $\alpha, \beta$-unsaturated $\gamma$-lactam and the description of its various reactivities. Then, the application to the total synthesis of alkaloids and namely of (-)-cephalotaxine will be presented.

\section{Chiral $\alpha, \beta$-unsaturated $\gamma$-lactam}

\subsection{Preparation}

We discovered, some 10 years ago, ${ }^{1}$ that the condensation of a primary amine with dimethoxydihydrofuran led to the formation of $\alpha, \beta$-unsaturated $\gamma$-lactam 1 . The reaction was conducted in acidic water at room temperature and proceeded via an oxidoreductive process. Indeed, this interesting reaction gave rise to the formation of two products: the conjugated lactam 1 and the unconjugated isomer. The latter was easily transformed, during work-up to the more stable derivative 1 (Scheme 1).

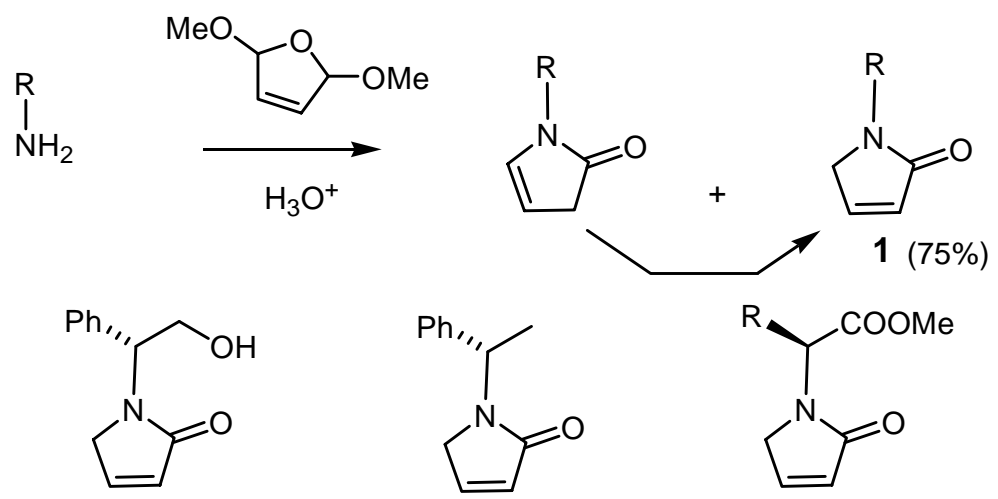

\section{Scheme 1}

This condensation reaction is quite general and can be applied to several chiral primary amines. Lactams derived from phenylglycinol, methylbenzylamine and several aminoesters were prepared in high yield. These $\alpha, \beta$-unsaturated $\gamma$-lactams $\mathbf{1}$ appeared as interesting starting 
material for the construction of various pyrrolidine derivatives thanks to the functionalities found onto their structures and allowing to attain most of the centres of the five-membered ring. Furthermore, the presence of a chiral centre may allow the construction of asymmetric structures through chiral induction.

\subsection{Reactivity}

The various reactivities of lactams 1 has been studied and will be briefly described.

Deprotonation of 1a, using two equivalents of a lithium base, followed by alkylation with a primary halide gave the alkylated product only at the C-3 position. The same alkylation process may be done twice: once again, the regioselectivity is complete and thus a quaternary center was formed (Scheme 2). The diastereoselectivity of this bis-alkylation was high with d.e. in the range $73-95 \%$. Changing the order of introduction of primary halides $\left(\mathrm{R}^{1} \mathrm{Hal}\right.$ and $\left.\mathrm{R}^{2} \mathrm{Hal}\right)$ allowed the change of the absolute configuration of the so-formed quaternary centre. The obtained products could be transformed to 3,3'-bisalkylated simple pyrrolidines, bisalkylated $\gamma$-aminoacids ${ }^{1}$

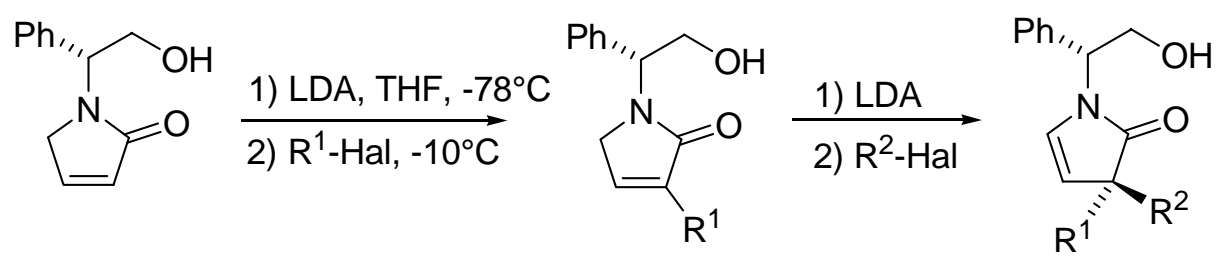

\begin{tabular}{cccc}
$\mathrm{R}^{1}$ & $\mathrm{R}^{2}$ & Yield (\%) & d.e. $(\%)$ \\
\hline $\mathrm{Me}$ & $\mathrm{Pr}$ & 45 & 95 \\
$\mathrm{Pr}$ & $\mathrm{Me}$ & 68 & 95 \\
$\mathrm{Me}$ & $\mathrm{CH}_{2} \mathrm{Ph}$ & 70 & 73 \\
$\mathrm{CH}_{2} \mathrm{Ph}$ & $\mathrm{Me}$ & 61 & 93
\end{tabular}

\section{Scheme 2}

Another very interesting reactivity of $\gamma$-lactam 1 was obtained upon treatment in acidic medium. As a matter of fact, $\mathbf{1 a}$ was quantitatively transformed into the bicyclic oxazolidine $\mathbf{2 a}$ when treated by $\mathrm{TsOH}$ or $\mathrm{HCl}-\mathrm{H}_{2} \mathrm{O}$ in dichloromethane for 2-3 h. This transformation resulted from the migration of the double bond (through the enol form) to the iminium ion which can be trapped by the alcohol moiety.

Bicyclic oxazolidine $\mathbf{2 a}$ is an acyliminium equivalent and could react with various nucleophiles in the presence of a Lewis acid (Scheme 3). Thus, allylation was obtained upon treatment with allyltrimethylsilane in the presence of $\mathrm{TiCl}_{4}$ in good yield and diastereoselectivity. Alkylation through cuprate reagents were also checked and occurred in good diastereoselectivity as well. ${ }^{2}$ 


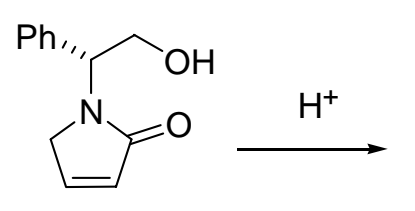

$1 \mathbf{a}$<smiles>O=C1C=C[C@H]2OC[C@@H](P)N12</smiles>

$2 \mathbf{a}$

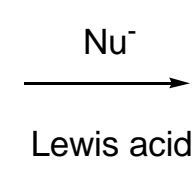

allylsilane, $\mathrm{TiCl}_{4}, \mathrm{CH}_{2} \mathrm{Cl}_{2}, 83 \%$ yield, $\mathrm{dr}=7: 1$

$\mathrm{MeCu}, \mathrm{BF}_{3}$.OEt, THF, 85\% yield, $\mathrm{dr}=7.8: 1$

nBuCu, $\mathrm{BF}_{3}$.OEt, THF, 95\% yield, dr = $7: 1$

\section{Scheme 3}

Lactams 1 could also be transformed into silyloxypyrrole $\mathbf{3}$ offering an interesting entry to vinylogous Mukaiyama-aldol type reaction. Lactam 1b furnished one of the first example of a chiral silyloxypyrrole (3b) allowing aldol reaction with aldehydes in good diastereoselectivity (Scheme 4). A total syn diastereoselectivity was observed (except for the smaller aldehyde: acetaldehyde) with a moderate to good facial diastereoselectivity depending upon the size of the aldehyde. ${ }^{3}$

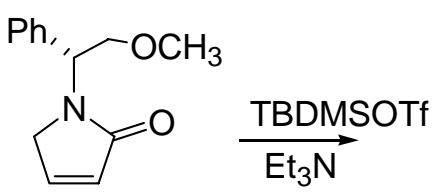

$1 b$<smiles>COCC(c1ccccc1)n1cccc1O[B-]S(C)(=O)=O</smiles>

$3 b$

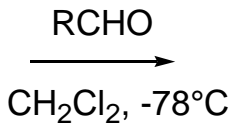

$\mathrm{BF}_{3} \cdot \mathrm{OEt}_{2}$<smiles>[R]C(O)[C@H]1C=CC(=O)N1C(COC)c1ccccc1</smiles>

4 (major)

\begin{tabular}{c|c|c}
$\mathbf{R}$ & Yield & RR/SS / RS / SS \\
\hline $\mathrm{CH}_{3}$ & 75 & $53 / 31 / 8 / 8$ \\
$\mathrm{C}_{2} \mathrm{H}_{5}$ & 63 & $64 / 36 / 0 / 0$ \\
$\mathrm{CH}_{2} \mathrm{Ph}$ & 59 & $75 / 25 / 0 / 0$ \\
$\mathrm{Ph}$ & 25 & $90 / 10 / 0 / 0$ \\
$t$-Bu & 56 & $93 / 7 / 0 / 0$
\end{tabular}

\section{Scheme 4}

It is noteworthy that a total regioselectivity at C-5 was observed for this reaction in sharp contrast with the alkylation reaction via the lithium enolate which gave C-3 alkylated products.

The reaction was extended to the condensation with imines. ${ }^{4}$ In that case, the use of ytterbium triflate as a catalyst was preferred. The diastereoselectivity was not so high as in the aldol type reaction but the major isomer could be isolated in good yield. The reaction was found to be anti selective. Moreover, the reaction could be performed in a three component-procedure. ${ }^{5}$ 
Thus, treatment of 3c, with an aniline and an aldehyde in the presence of catalytic amount of $\mathrm{Yb}(\mathrm{OTf})_{3}$ gave the Mannich type adduct 5 in high yield (Scheme 5).

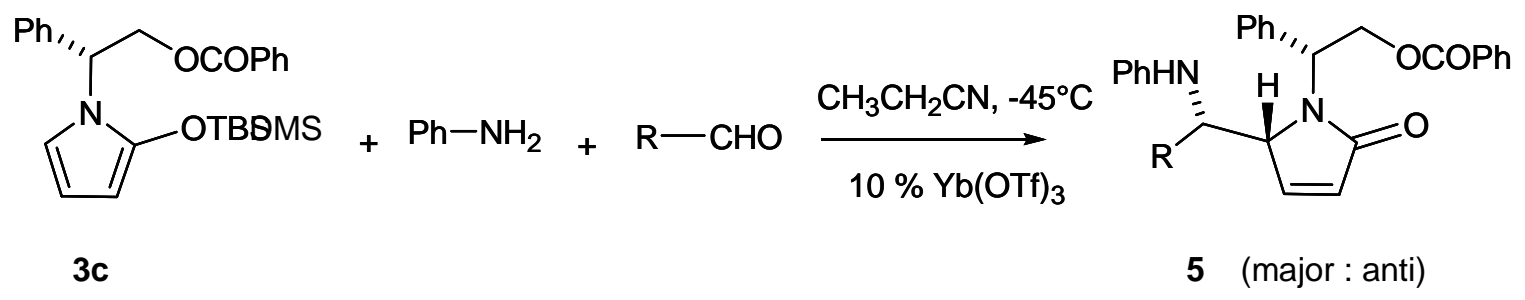

\section{Scheme 5}

\section{Application to the total synthesis of alkaloids}

\subsection{Asymmetric synthesis of polyhydroxylated pyrrolidines and indolizidines}

The use of chiral $\alpha, \beta$-unsaturated $\gamma$-lactam as starting material for the total synthesis of some simple alkaloids should be exemplified by the synthesis of polyhydroxylated pyrrolidines and indolizidines. A very rapid and efficient synthesis of 8a-epi-swainsonine was achieved starting from silyloxypyrrole 3c (Scheme 6).
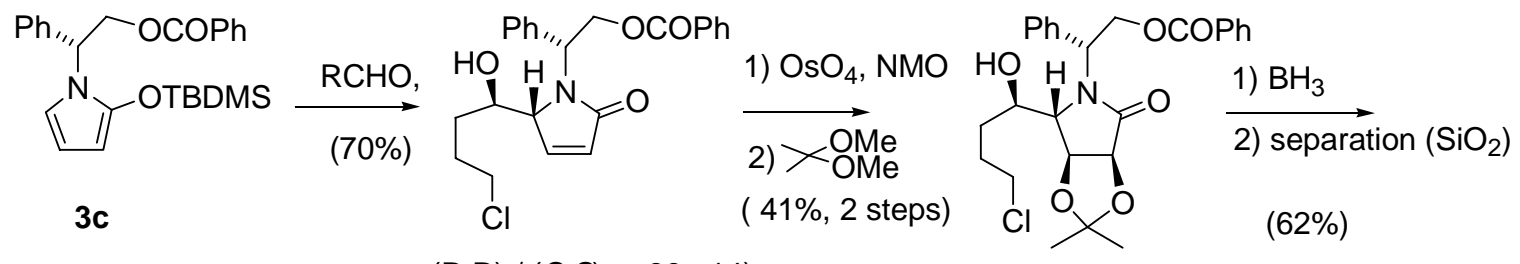

$$
(\mathrm{R}, \mathrm{R}) /(\mathrm{S}, \mathrm{S})=86: 14)
$$

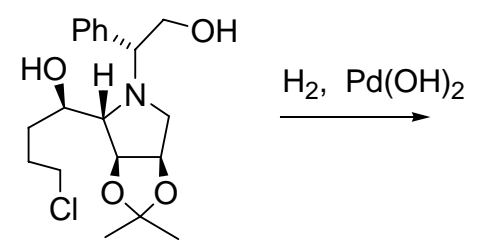

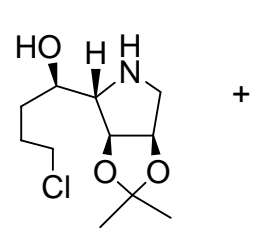

$(14 \%)$

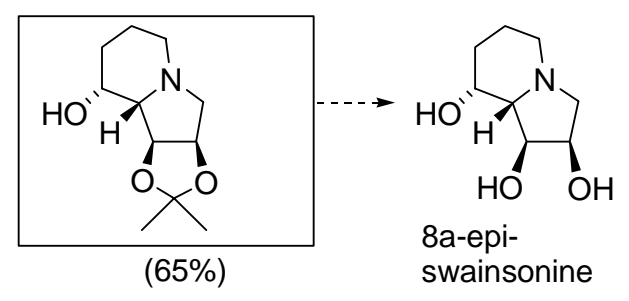

\section{Scheme 6}

The Mukaiyama reaction with 4-chlorobutyraldehyde gave the aldol adduct in a good yield and as a 86:14 diastereomeric mixture which is difficult to separate at that stage. The mixture was stereospecifically dihydroxylated and the diol protected before reduction of the lactam. The separation of diastereomeric amines was then quite easy and allowed the isolation of a single isomer in good yield. Hydrogenolysis of the chiral appendage was accompanied by spontaneous 
cyclization to the indolizidine skeleton of epi-swainsonine. ${ }^{6}$ Similar strategy was used to prepare aza-muricatacin. ${ }^{7}$

\subsection{Asymmetric synthesis of (-)-cephalotaxine}

\subsubsection{Cephalotaxine and homoharringtonine}

Cephalotaxine (6) is the major alkaloid isolated from several species of evergreen shrub of the genus Cephalotaxus. ${ }^{8}$ These plants also contains esters of cephalotaxine such as harringtonine (7) and homoharringtonine (8) which were isolated in minute amounts but found to exhibit very potent antileukemia activities. ${ }^{9}$ In particular, homoharringtonine is active on chronic myeloid leukemia (CML) a very severe disease for which very few treatments exist, and it was now in clinical trial phase 2 for this disease.<smiles>[R20]C1C(OC)=C[C@]23CCCN2CCc2cc4c(cc2[C@]13C)OCO4</smiles>

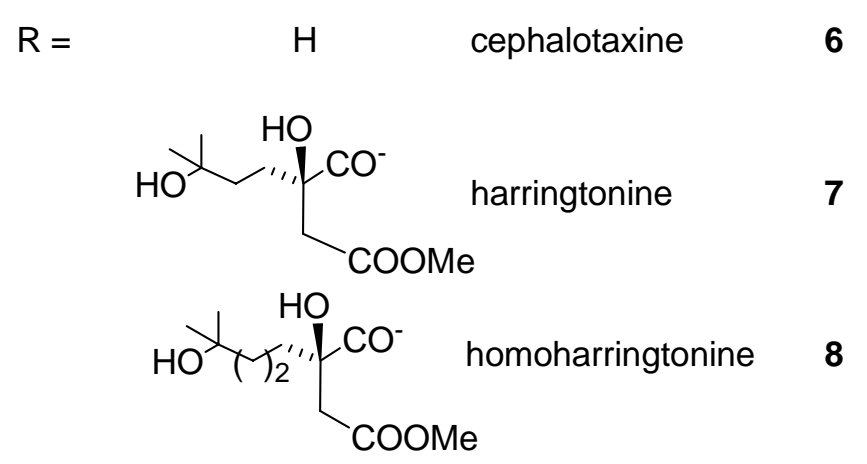

\section{Scheme 7}

\subsubsection{Previous total syntheses and enantiomeric purity}

While about a dozen of racemic syntheses of cephalotaxine have been reported, ${ }^{10}$ only four asymmetric syntheses have been achieved. ${ }^{11}$ Three of them gave the target alkaloid in $80-90 \%$ e.e. and no indication of enantiomeric purity was reported for the fourth one. ${ }^{11 \mathrm{~b}}$ The problem of the enantiomeric purity of this compound should be addressed. Indeed it has been reported that cephalotaxine could be racemized upon nitrogen quaternarization. ${ }^{12}$ Simple protonation leads to partial racemization and could explain that natural cephalotaxine is used to be isolated in about $90 \%$ e.e.

We propose the following mechanism of racemization (Scheme 8). Upon protonation, a Grobb type fragmentation could take place which destroy all the three chiral centres. The recyclization could then occur to give both possible enantiomers. 
<smiles></smiles>

(-)- cephalotaxine<smiles>I[IH+]</smiles>

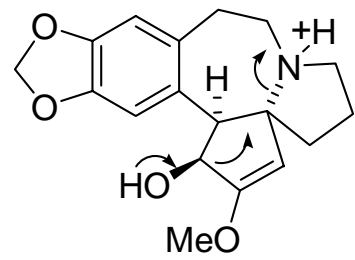
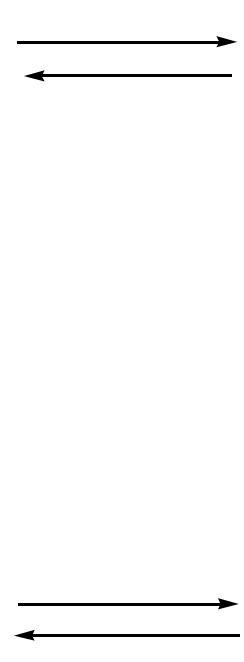<smiles>COC1=C[C@@H]2[C@H](O)c3cc4c(cc3CCN2CCC1)OCO4</smiles>

(+)- cephalotaxine<smiles></smiles>

\section{Scheme 8}

It was thus important to take into account this racemization problem in establishing a retrosynthetic scheme.

\subsubsection{Retrosynthesis}

The strategy we chose was based on the achievement of a method for the construction of the C/D ring moiety of cephalotaxine and more precisely on the development of an asymmetric access to the 1-azaspiro[4,4]nonane based on the chemistry of $\alpha, \beta$-unsaturated $\gamma$-lactam (Scheme 9)<smiles>[X]CCC1(CCN2CCCC23CC=C=CC3)CCCC1</smiles>

\section{Scheme 9}

To achieve our goal we think to use the dual reactivity we mentioned rending the C5 carbon atom of the pyrrolidone electrophilic or nucleophilic.

The semipinacolic rearrangement studied by Paquette ${ }^{13}$ to give spiro structures and applied to hydroxy-N-tosylenamine by Dake $^{14}$ (Scheme 10) was thought to be a good way to prepare 1azaspiro[4,4]nonane in an asymmetric fashion. 


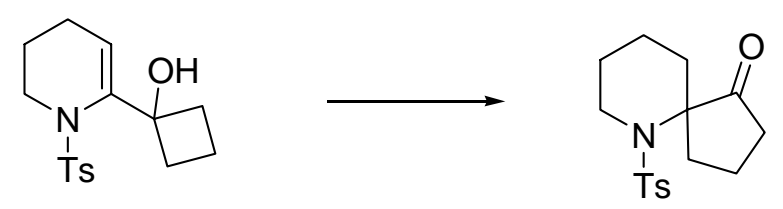

\section{Scheme 10}

\subsubsection{Synthesis of enantiomerically pure spiro compound}

The condensation of silyloxypyrrole $\mathbf{3}$ with cyclobutanone gave the expected aldol product in good yield and fair diastereoselectivity. The aldol product, upon acidic treatment furnished the semipinacolic rearrangement giving the spiro derivative in a nearly quantitative yield and with a poor diastereoselctivity (65:35) (Scheme 11).

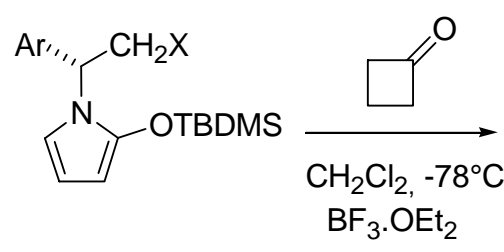

$\mathrm{Ar}=\mathrm{Ph}$, Napht. $\mathrm{X}=\mathrm{H}, \mathrm{OCH} 3$

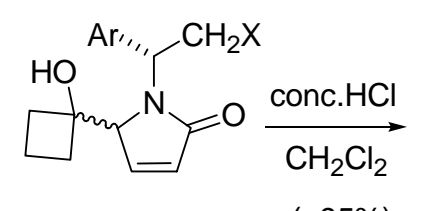

$(>95 \%)$

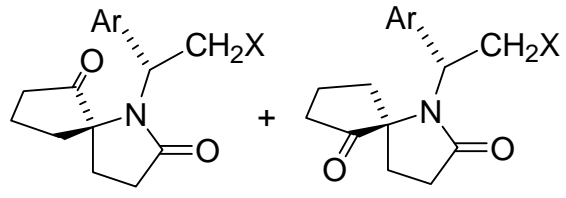

9

major

\section{Scheme 11}

We thus decided to investigate several chiral auxiliaries with the aim to improve this diastereoselectivity. Eventually, good diastereoselectivity was obtained starting from silyloxypyrrole 3d prepared from (S)-1-(1-naphthyl)ethylamine. The vinylogous Mukaiyama aldol reaction of $\mathbf{3 d}$ with cyclobutanone, combined with acidic treatment furnished the desired spiro derivative 9 in $77 \%$ yield ( 2 steps) and a nice $80 \%$ d.e. The major diastereoisomer could be crystallized from ethanol allowing the isolation of pure major isomer in $86 \%$ yield. ${ }^{15}$

\subsubsection{Completion of the synthesis of (-)-cephalotaxine}

The completion of the total synthesis of (-)-cephalotaxine was realized by following the racemic synthesis described by Kuehne ${ }^{16}$ and is briefly resumed in the following scheme (Scheme 12). The main steps included the cleavage of the chiral auxiliary and the introduction of the methylenedioxyphenylethyl side chain. Cyclization of the aromatic group was made on an allylic alcohol to form the seven membered ring: this cyclization occurred only on one face of the ring. 


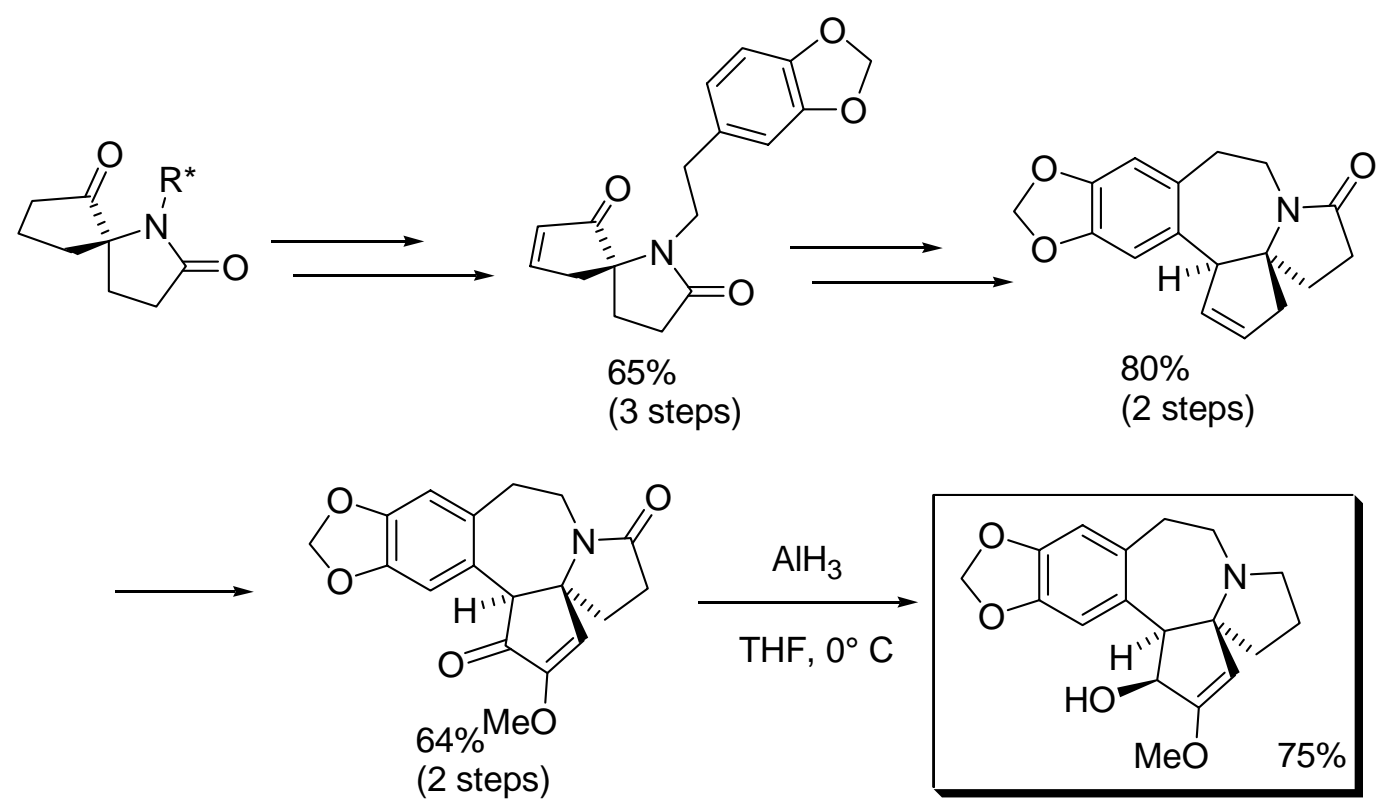

\section{Scheme 12}

We were confident to be able to circumvent the racemization problem that we pointed out since until the last step there is no free amine. We just went on the last reduction step very carefully using aluminum hydride that allowed conducting the reaction at low temperature.

These conditions furnished a 75\% yield of (-)-cephalotaxine. The synthesis was thus achieved in 16 steps and a $9.8 \%$ overall yield. ${ }^{17}$

The enantiomeric purity was carefully checked by chiral HPLC showing that the synthetic material exhibits a $98.7 \%$ ee.

\section{Conclusions}

In conclusion, chiral $\alpha, \beta$-unsaturated $\gamma$-lactam was proved to be an interesting starting material for the construction of variously substituted pyrrolidine containing compounds. The chiral induction is good to excellent. The combination of the various reactivities of chiral $\alpha, \beta$ unsaturated $\gamma$-lactam allows the construction of more complex polycyclic structures.

\section{Acknowledgements}

The authors thank the CNRS and the French Ministry of Research for funding. 


\section{References and Notes}

1. Baussanne, I.; Chiaroni, A.; Riche, C.; Royer, J.; Husson, H.-P. Tetrahedron Lett. 1994, 35, 3931.

2. Baussanne, I.; Chiaroni, A.; Royer, J. Tetrahedron : Asymmetry 2001, 12, 1219.

3. Baussanne, I.; Royer, J. Tetrahedron Lett. 1996, 37, 1213.

4. Dudot, B.; Royer, J.; Sevrin, M.; George, P. Tetrahedron Lett. 2000, 41, 4367.

5. Dudot, B.; Chiaroni, A.; Royer, J. Tetrahedron Lett. 2000, 41, 6355.

6. Dudot, B.; Micouin, L. ; Baussanne, I.; Royer, J. Synthesis 1999, 688.

7. Baussanne, I.; Schwardt, O. ; Royer, J. ; Pichon, M. ; Figadere, B. ; Cavé, A. Tetrahedron Lett. 1997, 38, 2259.

8. Paulder, W. W. ; Kerley, G. I.; McKay, J. J. Org. Chem. 1963, 28, 2194.

9. Hitt, E. Lancet Oncol. 2002, 3, 259

10. (a) Jilal Miah, M. A. ; Hudlicky, T. ; Reed, J. W. In The Alkaloids, Cordell, G. A., Ed.; Academic Press: San Diego, 1998, Vol 51. (b) Kim, S. H.; Cha, J. K. Synthesis 2000, 2113.

(c) Booker Milburn, K. I.; Dudin, L. F.; Anson, C. E.; Guile, S. D. Org. Lett. 2001, 3, 3005.

(d) Tietze, L. F.; Steck, P. L. Eur. J. Org. Chem. 2001, 4353. (e) Worden, S. M.; Mapitse, R.; Hayes, C. J. Tetrahedron Lett. 2002 , 43, 6011.

11. (a) Isono, N.; Mori, M. J. Org. Chem. 1995, 60, 115. (b) Nagasaka, T.; Sato, H.; Saeki, S.-I. Tetrahedron: Asymmetry 1997, 8, 191. (c) Ikeda, M.; el Bialy, S. A.; Hirose, K.; Kotake, M.; Sato, T.; Bayomi, S. M.; Shehata, I. A.; Abdelal, A. M.; Gad, L. M.; Yakura, T. Chem. Pharm. Bull. 1999, 47, 983. (d) Tietze, L. F.; Schirok, H. J. Am. Chem. Soc. 1999, 121, 10264.

12. Abraham, D. J.; Rosenstein, R. D.; McGandy, E. L. Tetrahedron Lett. 1969, 10, 4085.

13. Paquette, L. A.; Negri, J. T.; Rogers, R. D. J. Org. Chem. 1992, 57, 3947.

14. Fenster, M. D. E.; Patrick, B. O.; Dake, G. R. Org. Lett. 2001, 3, 2109.

15. Kuehne, M. E.; Bornmann, W. G.; Parson, W. H.; Spitzer, T. D.; Blount, J. F.; Zubieta, J. J. Org. Chem. 1988, 53, 3439.

16. Planas, L. ; Pérard-Viret, J.; Royer, J.; Selkti, M.; Tomas, A. Synlett 2002, 1629.

17. Planas, L. ; Pérard-Viret, J.; Royer, J. J. Org. Chem. 2004, 69, 3087. 